$1060 \mathrm{~nm}$ and $1310 \mathrm{~nm}$ Vernier-Tuned Distributed Bragg Reflector (VT-DBR) Lasers for Swept-Source OCT

\title{
C INSIGHT
}

Abstract

Introduction to VT-DBR Lasers

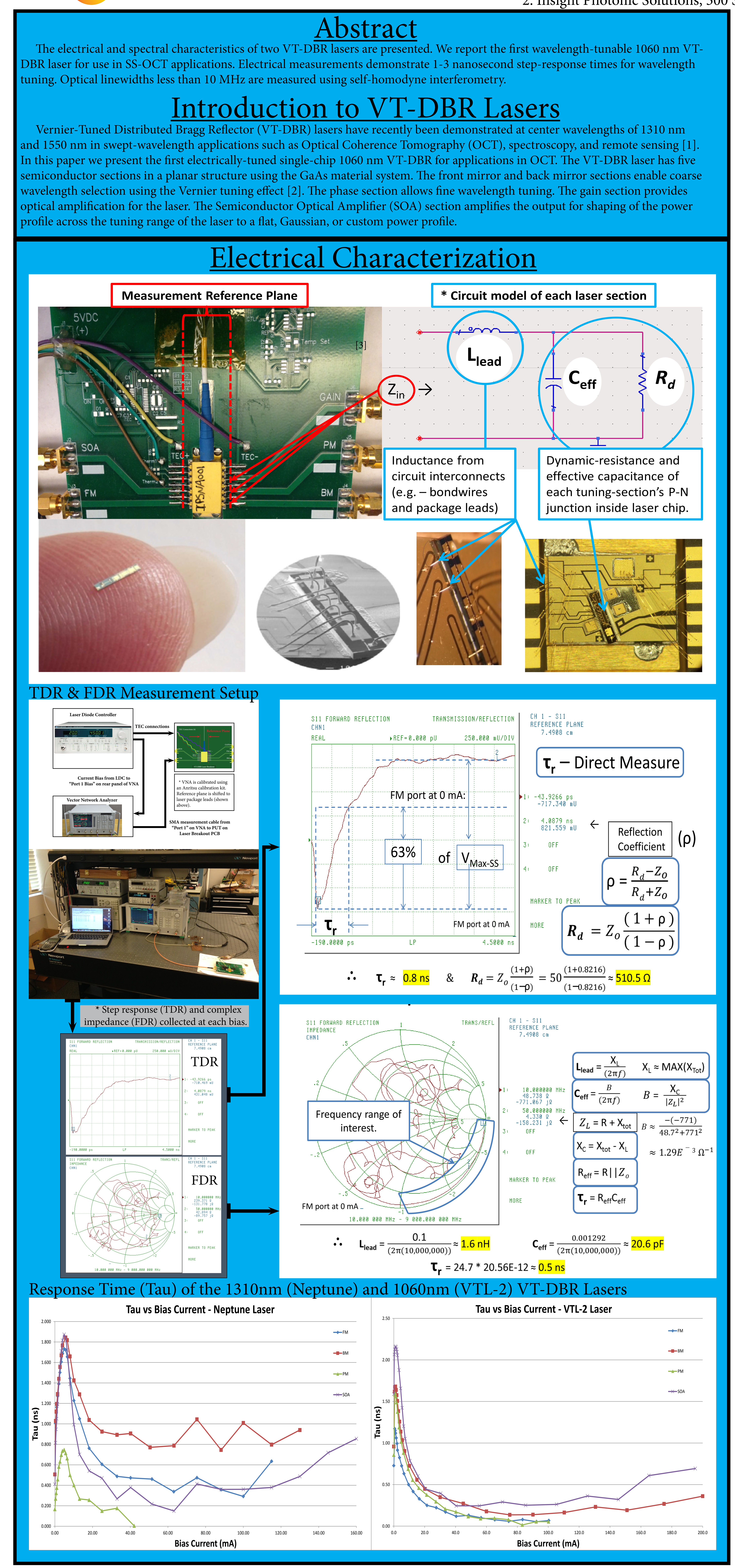

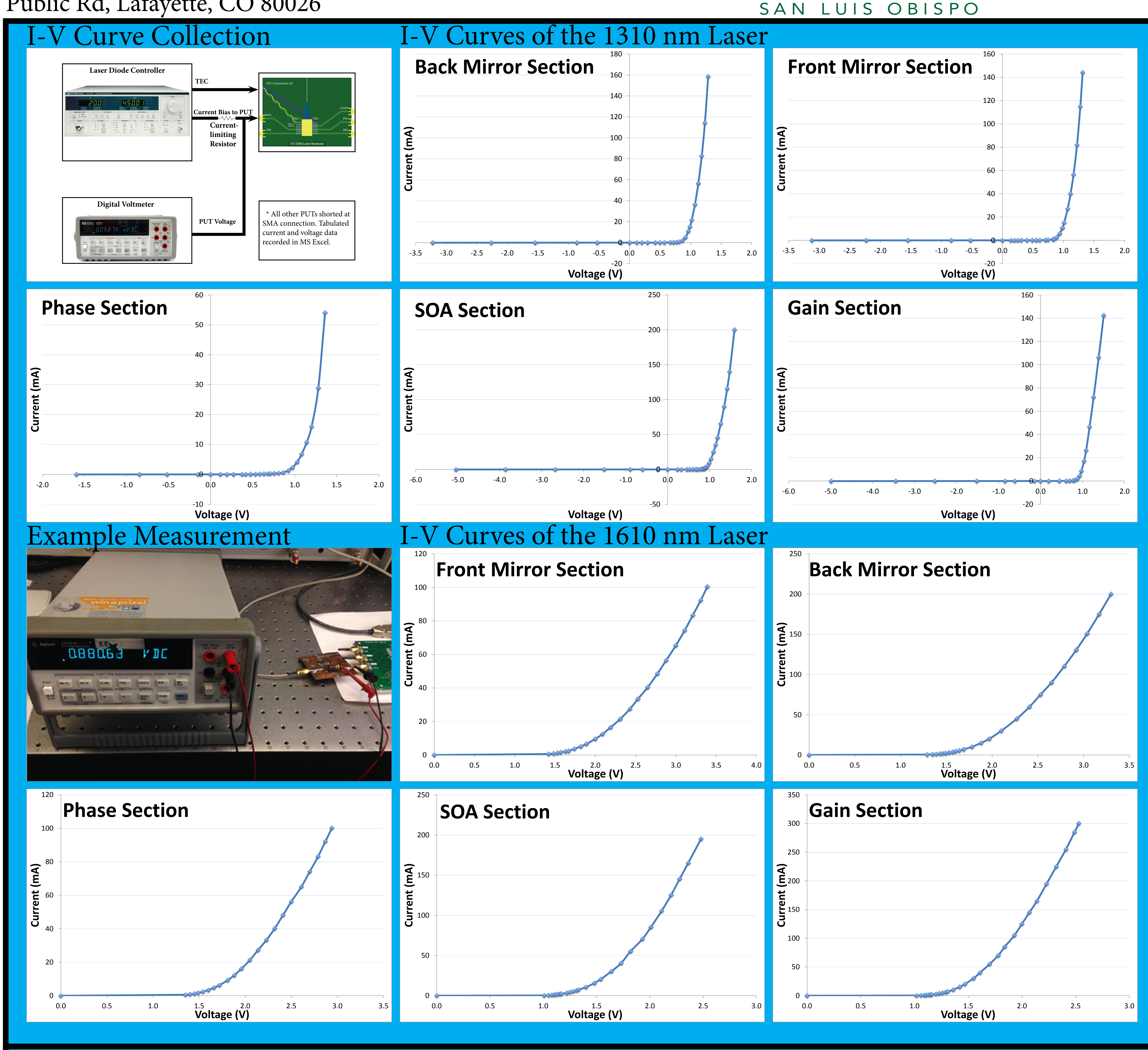

Spectral Characterization
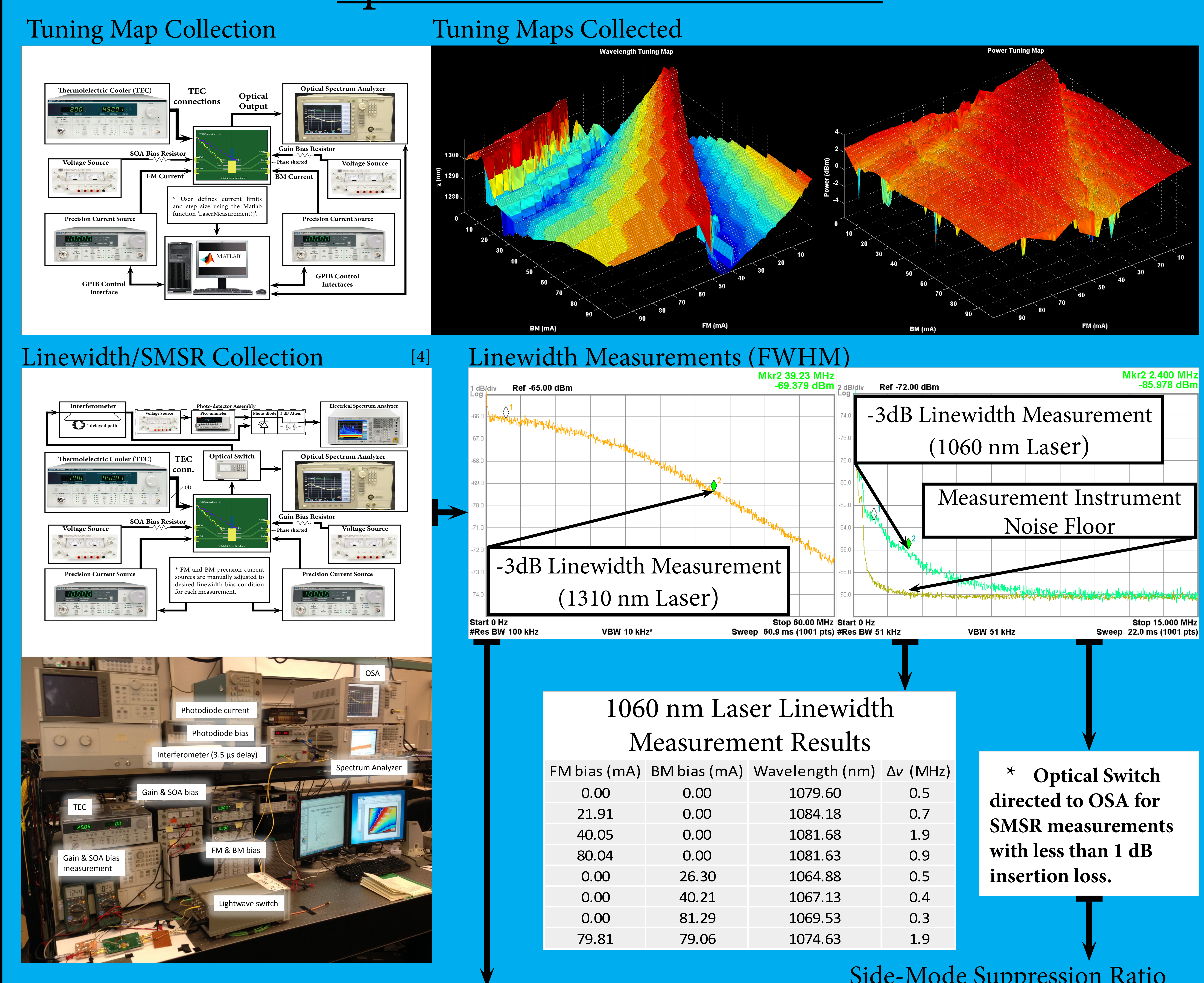

$1310 \mathrm{~nm}$ Laser Linewidth Measurement Results

Data-set \#1: PM segment shorted

Data-set \#2: FM \& PM shorted

Data-set \#3: BM \& PM shorted

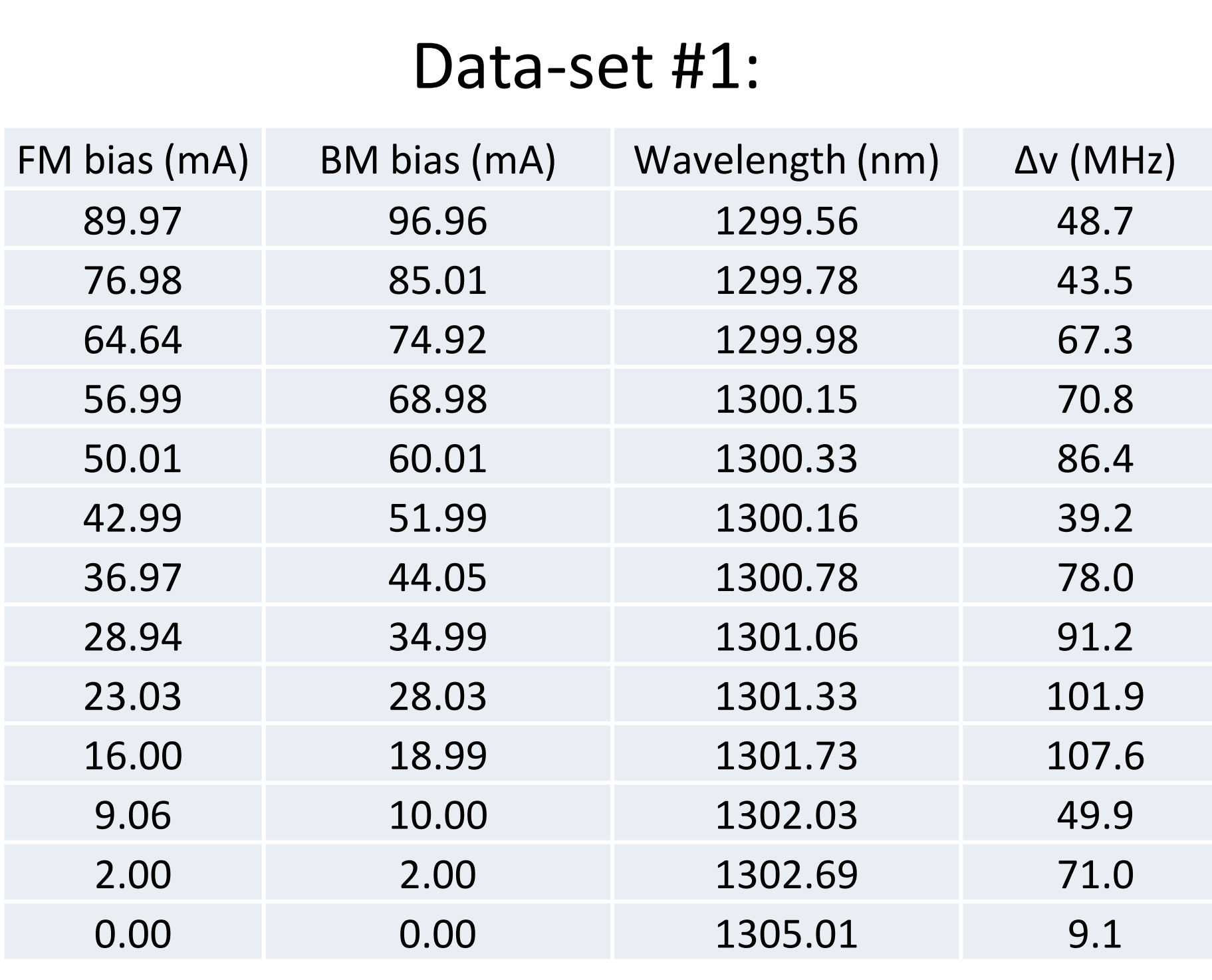

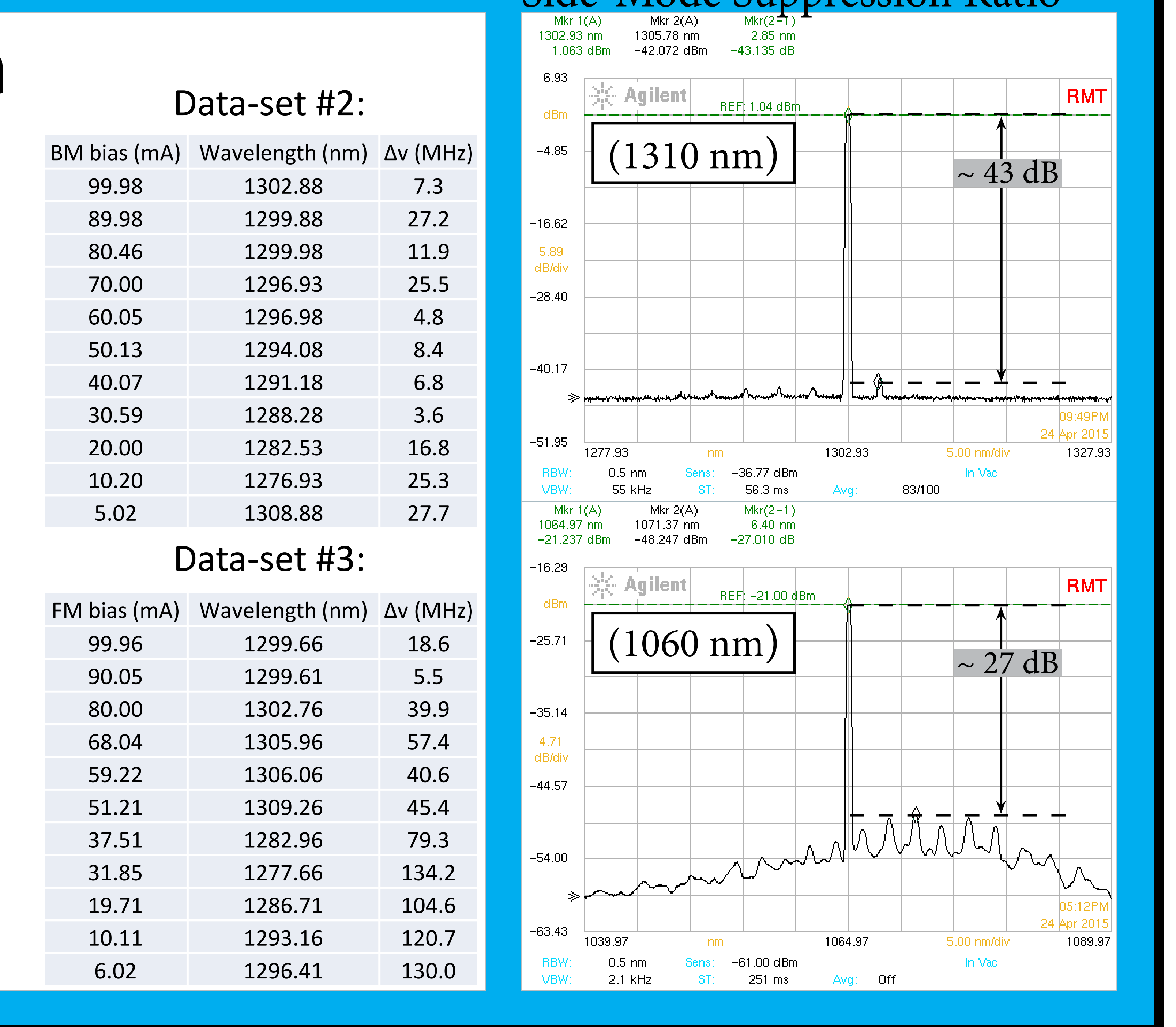

